dependent factors, admits that the whole subject is "still in its infancy".

Finally, a series of articles relating to birds and man includes all the issues arising from modern conceptions of conservation and protection, and the dangers attendant on introductions of exotic species.

For many years and even decades this impressively authoritative addition to ornithological literature will hold the field. Long before the British Ornithological Union celebrates its second centenary and contemplates another new dictionary, many and perhaps most of the unresolved scientific questions so ably discussed and now left open will have found their answer. Whether the variety, range and abundance of the world's birds and of habitats suitable for most of them will still be as fascinating for ornithologists to study and bird-watchers to enjoy a century hence is a speculation on which it is not possible to embark without misgiving and even anxiety.

HURCOMB

\section{EARTH SCIENCES}

\section{The Planet Earth}

Edited by Prof. D. R. Bates. Second edition, revised and enlarged. Pp. vii +370 . (London and New York: Pergamon Press, 1964.) 42s. net.

\section{The Earth Sciences}

By Prof. Arthur N. Strahler. (Harper's Geoscience Series.) Pp. xii +671. (New York, Evanston, and London: Harper and Row, 1963.) 75s.

Introduction to Satellite Geodesy

By Prof. Ivan I. Mueller. Pp. xxi +415. (New York: Frederick Ungar Publishing Co.; London: Constable and Co., Lt.d., 1964.) 15 dollars; $120 s$.

\section{Gravitation and Relativity}

Edited by Dr. Hong-Yee Chiu and Dr. William F. Hoffmann. (Physical Investigations of the Universe.) Pp. $\mathrm{xxxy}+$ 353. (New York and Amsterdam: W. A. Benjamin, Inc., 1964.) 15.75 dollars.

THESE four books are of considerable interest to workers in the Earth sciences.

The Planet Earth, edited by Prof. Bates, has been published in a second edition. It is a useful survey in 18 chaptors of the separate aspects of the physics of the Earth and its environment. Although in the preface to this edition it is stated that there has been considerable revision of the chapters to bring them up to date, there has, in the interval of six years, been revolutionary advance in many of the topics under discussion and the revision has in many cases not been sufficiently thorough. However, it is a book which should be read by all students of geophysics.

The Earth Sciences, by Prof. Strahler, is of a much more elementary level and is intended as an introduction to be read by students in American university departments of geology. It is extraordinarily well illustrated with much useful graphical presentation and some remarkable photographs. What is perhaps important in relation to teaching in geology departments in Britain is that geophysical and astronomical topics are tackled in detail and I think the treatment is successful. The presentation of meteorological, astronomical and oceanographical prineiples to students of geology who often have not specialized in physics and mathematics is difficult, and Prof. Strahler is to be congratulated on his attempt to present physical explanations in simple terms by very excellent illustrations.

The other two books are of a more specialized nature. The Introduction to Satellite Geodesy, by Prof. Mueller, is of great importance. The accurate determination of the small divergences of the Earth from hydrostatic equili- brium will probably provide the solution to many of the more important questions in geophysics during the next few years. The question whether or not convection currents are occurring in the mantle of the Earth, and if so what their distribution is, is likely to be solved in this way.

The book by Dr. Chiu and Dr. Hoffmann on Gravitation and Relativity may seem to have little interest for the geophysicist. However, in the past the investigation of the solar system has revealed fundamental laws of physies which could not easily have been discovered in the laboratory. The geophysicist should not always assume that he is simply concerned with the application of the known laws of physics to explain natural phenomena. The distinguished contributions in the book by Prof. Dicke and Prof. Wheeler concern fundamental difficulties in the theory of gravitation, to the discussion of which geophysical data on the evolution of the Earth-Moon system may still produce a notable contribution.

S. K. RunconN

\title{
ASPECTS OF RELATIVITY
}

\section{The Theory of Space, Time and Gravitation}

By V. Fock. Translated from the Russian by N. Kemmer. Second revised edition. Pp. xii +448 . (Oxford, London, Now York and Paris: Pergamon Press, 1964.) 100s.

THE first edition in English of The Theory of Space,

Time and Gravitation, published in 1958, was greeted as an important and original contribution to the literature; in subsequent years Prof. Fock's book has continued to be held in high regard, proving itself worthy of its initial acclaim. The recent publication of the second revised edition of this masterly work is indeed to be welcomed.

Ably translated from the Russian by Prof. Kemmer, this book includes, within its role as a text-book for the graduate student in theoretical physics, the author's own powerfully argued and highly distinctive views and interpretations of the subject of relativity. It is a thorough exposition of what are usually called the special and general theories, although Fock insists that these are misnamed. Using the word 'relativity' to denote an invariance in the description of physical processes in different frames of reference, Fock justifies instead the nomenclature 'the theory of relativity' and 'the theory of gravitation', by pointing out that the principle of relativity is directly related to uniformity and that Galilean space has maximal uniformity.

The first four of the seven chapters of the book are devoted to the development of the theory of (special) relativity, including its formulation in tensor form. The remaining chapters, rather more controversial in character, deal with Fock's own interpretation of the foundations and principles of Einstein's theory of gravitation.

In its non-cosmological form, this is based on the hypothesis that the goometrical properties of real, physical space and time correspond to Riemannian, rather than Euclidean, geometry, any deviation from the pseudoEuclidean form appearing as a gravitational field. Throughout the work, Fock is concerned with ensuring the uniqueness of this result, and he deals with the problem of boundary conditions by combining with the above hypothesis the assumption that there is an insular distribution of masses, so that the geometry at points far removed from the masses is Euclidean. (When the cosmological problem is briefly discussed in Sections 94 and 95, this assumption is replaced by that of a uniform distribution, which leads to a Friedmann-Lobachevsky space.)

The field equations then follow from a generalization of Newton's laws, and the remainder of the book deals, in the main, with the derivation of the equations of motion and with gravitational potentials. Much of the complexity 